\title{
المراكز البحثية ودورها في صنع السياسة الحارجية المغربية
}

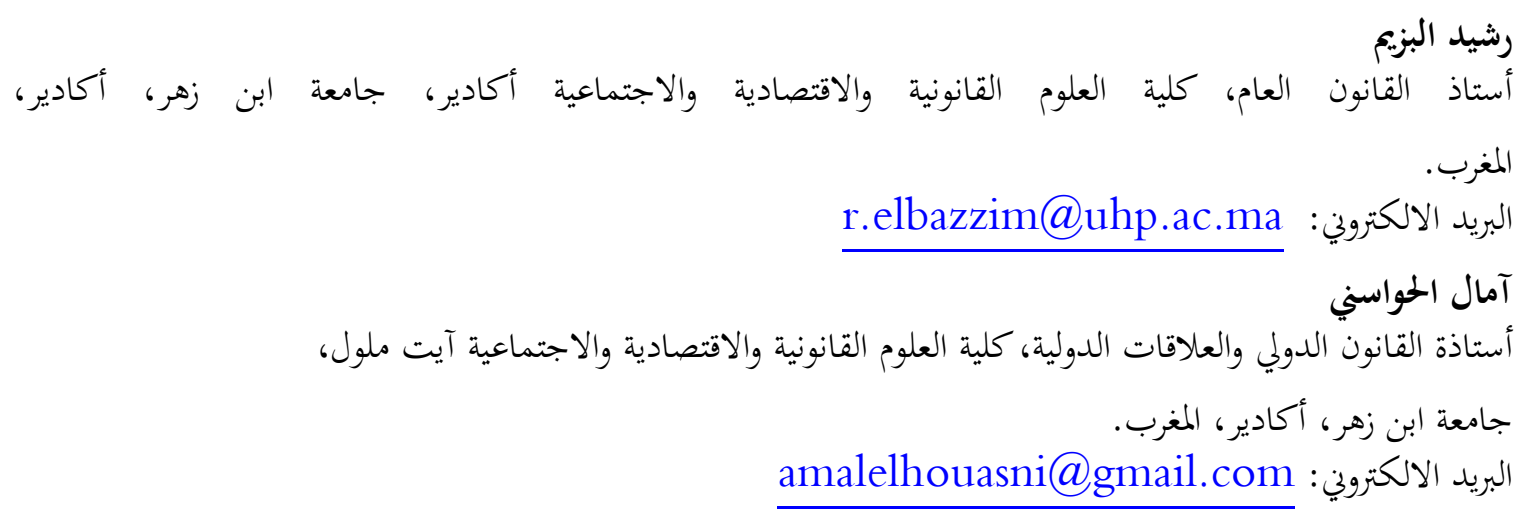

نبذة مختصرة عن الباحثين:

السيد رشيد البزيم أستاذ القانون العام بجامعة ابن زهر، أكادير (المغرب)، حاصل على الدكتوراه في

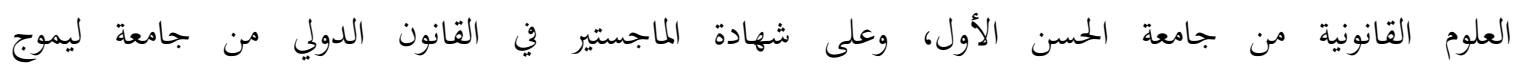
بفرنسا. صدر له مؤخراً: Reinventing the Moroccan state and the implementation of the independent regulatory agencies (IRAs) (Católica Law Review, 2020)

DOI: https://doi.org/10.34632/catolicalawreview.2020.6968

Conseil de la concurrence au Maroc : de la recherche de l'indépendance à la régulation du marché (l'Harmattan, 2019)

السيدة آمال الحواسني أستاذة القانون الدولي والعلاقات الدولية بكلية العلوم القانونية والاقتصادية

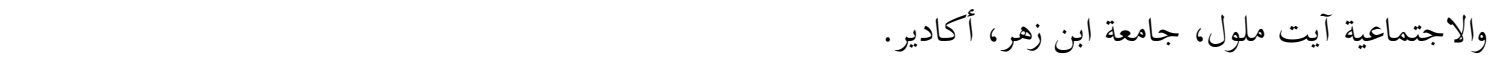

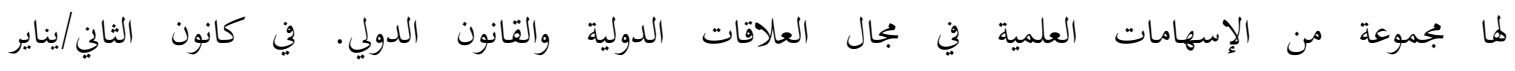

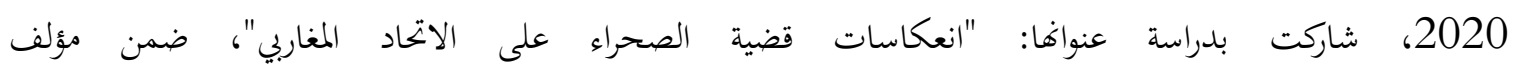

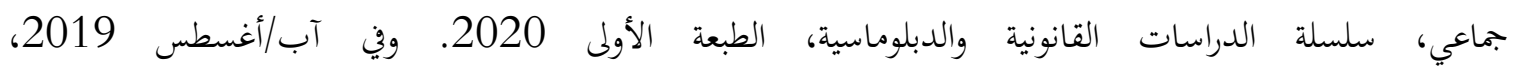

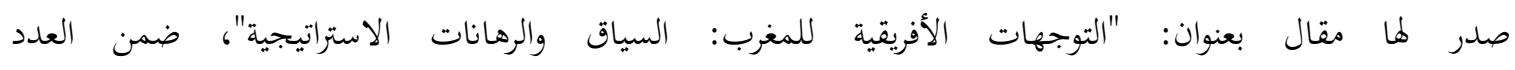

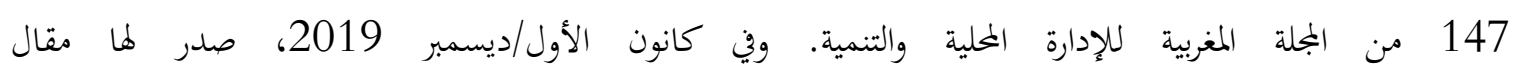

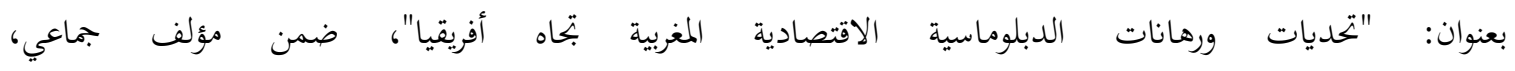
المطبعة والوراقة الوطنية، مراكش، الطبعة الأولى 2019. 
تحتل مراكز الأبحاث مكانة خاصة في مجال صنع القرار السياسي، حيث تعتمد عليها الدول لتقد يم دراسات وتقارير واستشارات في جلّ الميادين. تعتبر دراسة القضايا والمشكلات التي تواجه الدولة

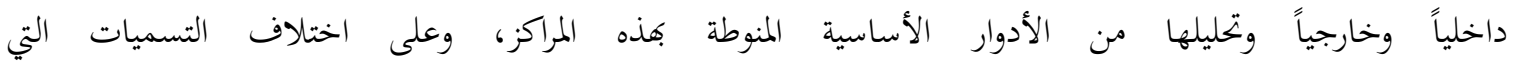

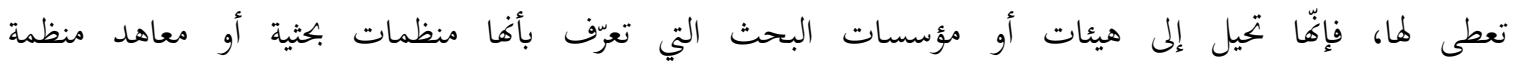

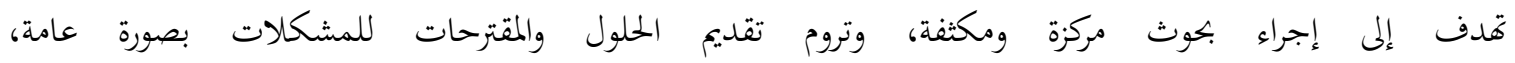

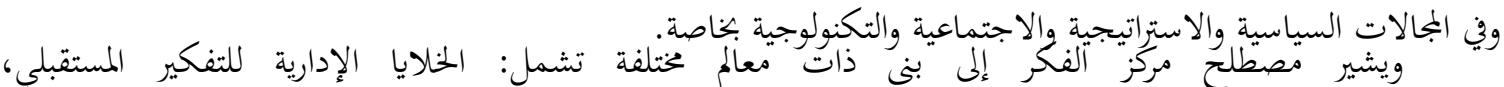

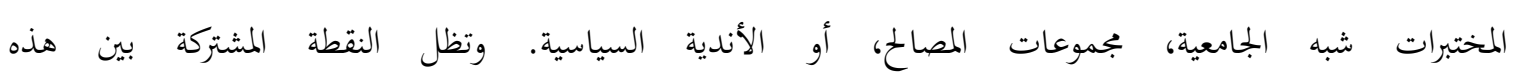

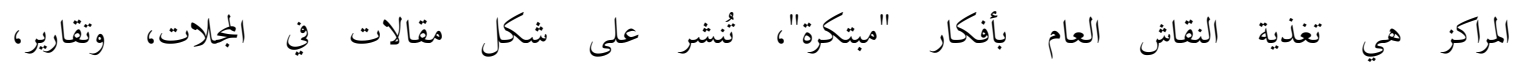

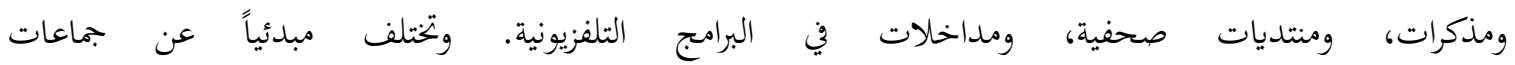
الضغط، حيث لا تمدف مراكز الفكر للدفاع عن مصالح مخفية، بل إلى التعبير عن وجهة نظر الباحثين الجماعية بشكل علني. كما تتميز عن البنى الجامعية أيضاً بالرغبة والحاجة المطلقة إلى نشر أعمالها في الإعلام.

ويعتبر حقل السياسة الخارجية مجالاً خصباً لمراكز صنع الاستراتيجيات، حيث نشأت في العالم الأنكلوسكسوني، كمنظمات شبه حكومية تمارس مهام استشارية في مجالي العلاقات الدولية والدفاع. وهكذا تم إنشاء المعهد الملكي للشؤون الدولية في إنكلترا في العام 1919، في أعقاب الحرب العابمية الأولى. وتطورت الظاهرة في الولايات المتحدة بعد الحرب العالمية الثانية، عندما تعلق الأمر بتطوير

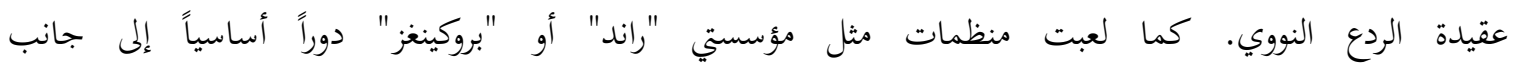
الحكومة الأمريكية في صياغة السياسات الخارجية والعسكرية. وبحلول السبعينيات وبدايات الأزمة

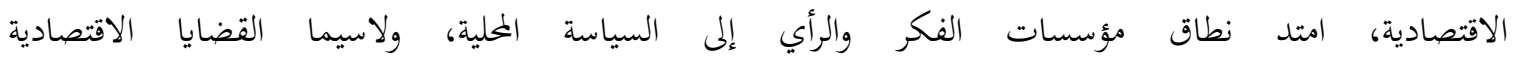
والاجتماعية. في فرنسا، تحتل بعض مراكز الفكر حيزاً مهماً في مجال السياسة الدولية، مثل المعهد الفرنسي للعلاقات الدولية (IFRI) الذي أنشئ في السبعينيات. وهو يستفيد من الإعانات العامة، لكنّ الجزء الأكبر من تمويله (حوالي 60 بالمئة) يأتي من الخواص، في بلد يتسم بمركزية سياسته، وسيادة ما يعرف بالدولة الاستراتيجية.

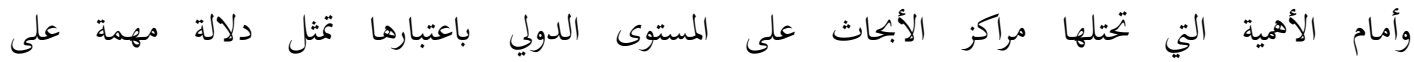

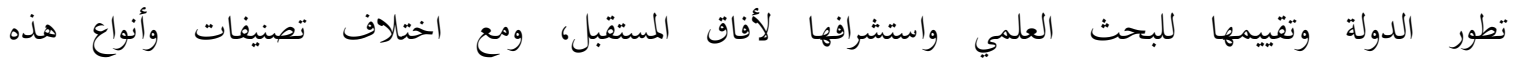

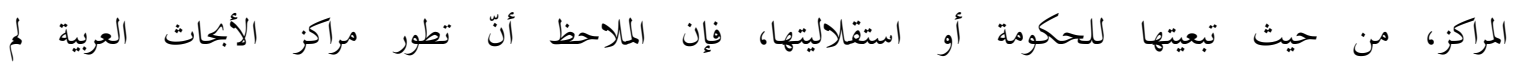
وانطلاقاً من ذلك، تحراورل الفكر هذبة (همود، الورقة البحثية تسليط الضوء على مراكز التفكير التي تشتغل على السياسية الخارجية المغربية، لمساءلة دور هذه المراكز في إنتاج المعرفة وفي دعم التوجهات الرئيسية 
للسياسة الخارجية المغربية، في ظل هيمنة الدبلوماسية الرسمية على صنع هذه السياسة باعتبارها بجالاً

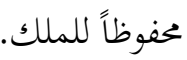
تزامناً مع التطورات التي شهدها الخطاب التكنوقراطي في مجال السياسة الخارجية المغربية

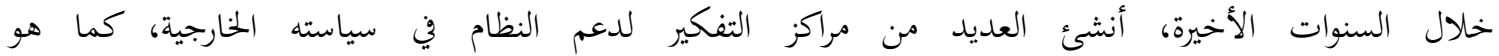

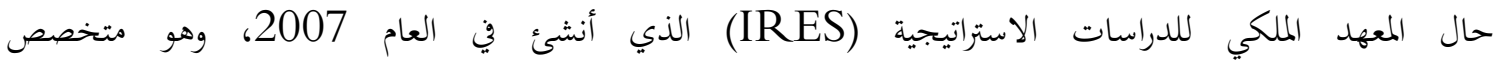

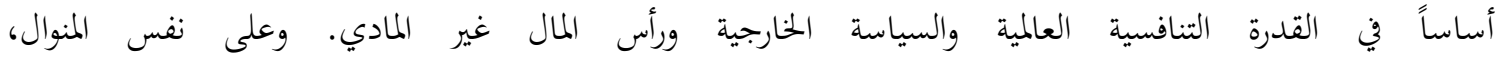

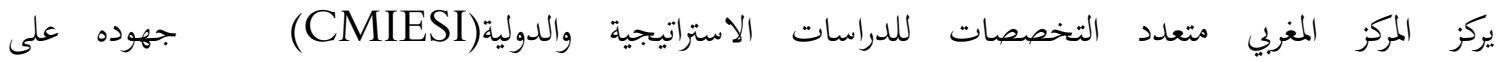
دراسة الهيكلة الإقليمية والحكم الحلي. من جانبه، يركز معهد أماديوس (AMADEUS)الذي تأسس النسات

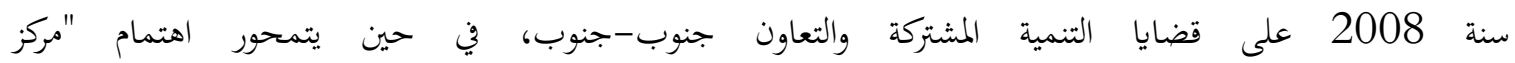
السياسات من أجل الجنوب الجديد" (Policy Center for the New South) الذي تأسس سنة 2014 والتابع لمجمع الشريف للفوسفات على إنتاج الخبرة للإسهام في تطوير السياسات العمومية والتوجهات الدولية للمغرب وبقية الدول الأفريقية.

فمن خلال إشراك هذه الشبكة من مراكز البحوث في قرارات السياسة الخارجية، يتم التأكيد على التية

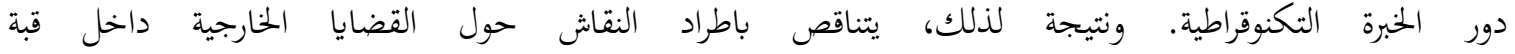

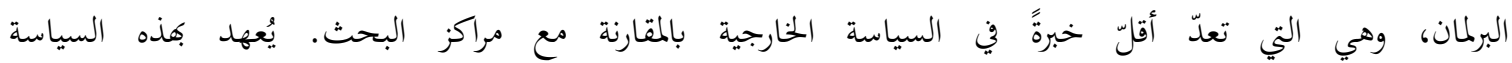
إذاً إلى الخبرة التكنوقراطية التي تخضع لمراقبة الدبلوماسية الرسمية.

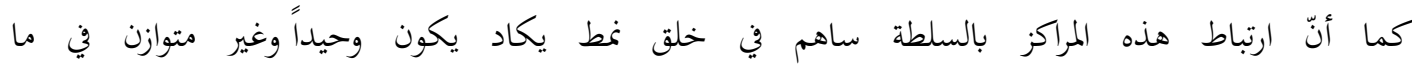

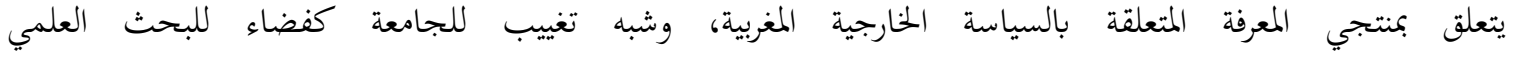
الرصين. بحيث لا يقتصر الصراع بين الفاعلين على استقطاب الموارد وتنظيم أسس البحث، وإنما يمسّ تعريف ما هو علمي وما هو غير علمي، ما ينتمي إلى المعرفة الشرعية وما يتم اقصاؤه عنها.

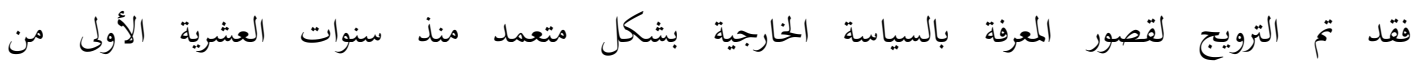

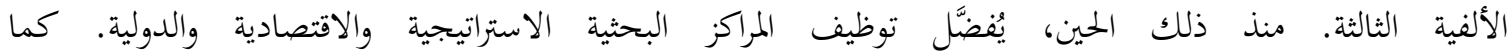

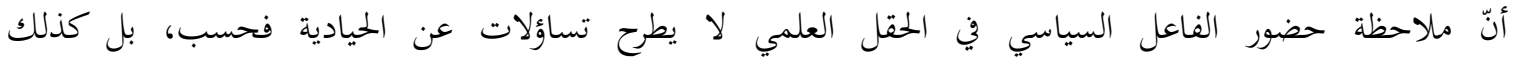

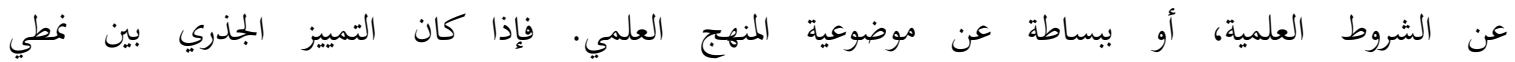

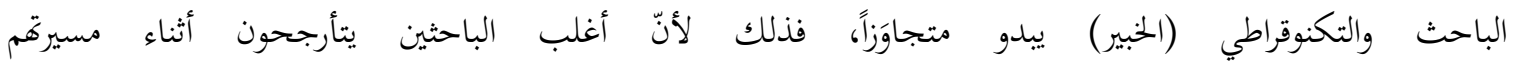

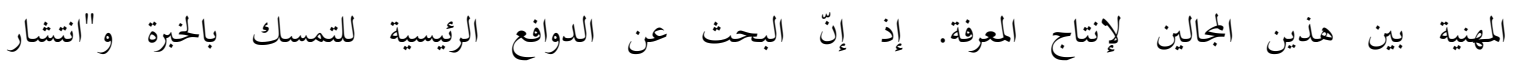
البحث حسب الطلب" يمكن أن يمملا بين طياتما الرغبة في عدم تسييس حقل السياسة الخارجية، وجعله حكراً على جهة فاعلة وحيدة، مقابل إقصاء فاعلين آخرين.

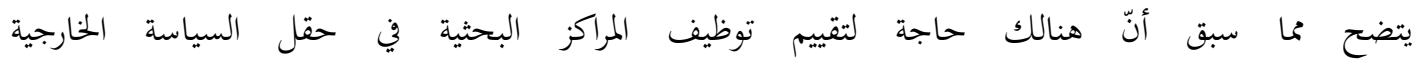

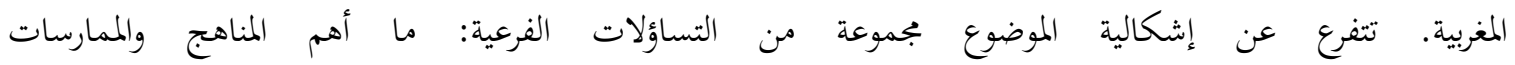

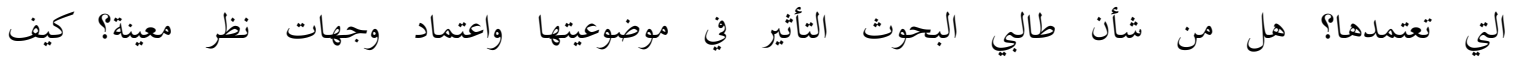


يوظف الفاعل السياسي ما هو علمي لخدمة أجندته؟ وهل البحث في تخصص السياسة الخارجية

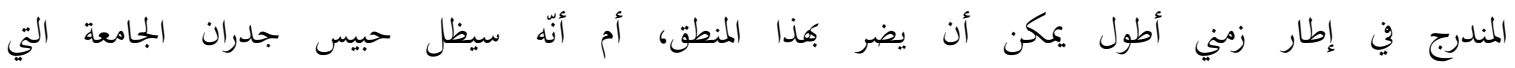
أنتجته؟ من جانب آخر، هل هنالك ترابط وتغذية راجعة بين بجالات إنتاج المعرفة هذه، وكيف يستطيع

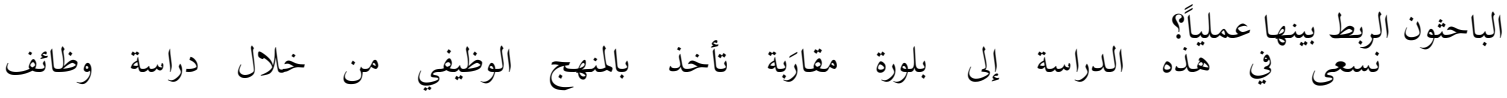

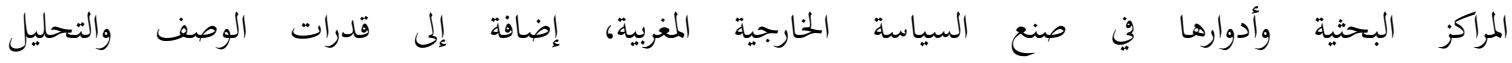
لمعالجة هذا الموضوع، وذلك انطلاقاً من رصد السياقات التي عرفت نشأة المراكز البحثية المذكورة

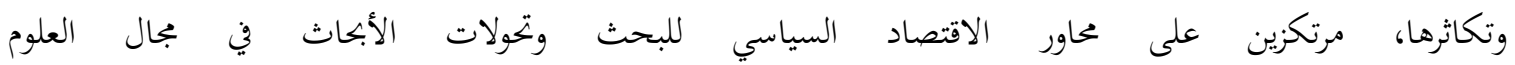

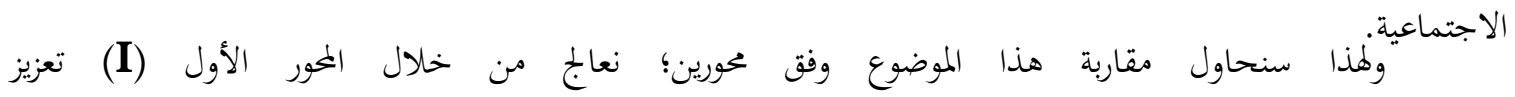

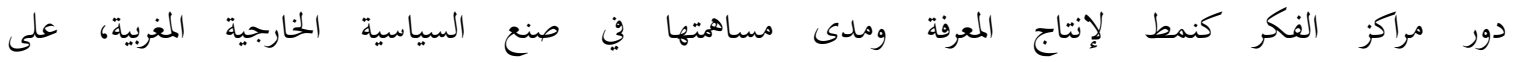
أن نخصص المور الثاني (III) للجامعة المغربية وأسباب تراجع مكانة العلوم الاجتماعية فيها. ت تزايد الطلب على مراكز البحث وصنع السياسة الحارجية المغربية ظهرت في السنوات الأخيرة في المغرب مراكز فكر كثيرة، سعت لإغناء النقاش العمومي حول السياسات العامة، كما هدفت إلى إضفاء نوع من الحداثة على مؤسسات البلد وثقافته السياسية. ويمكن

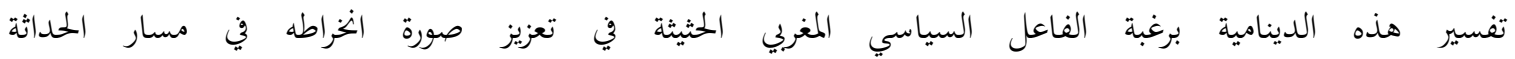

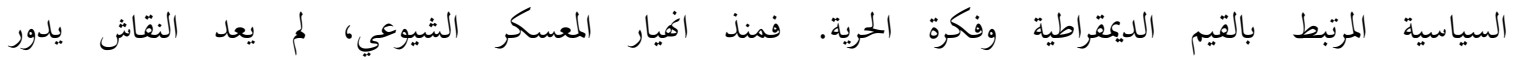

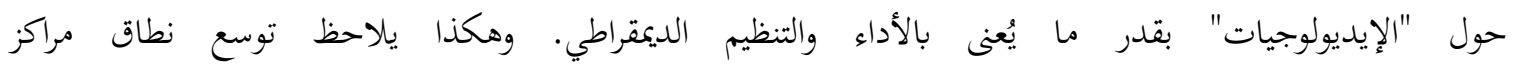
الفكر، وهي تعمل من أجل صياغة مقترحات ملموسة وواقعية للتأثير في صانعي القرار.

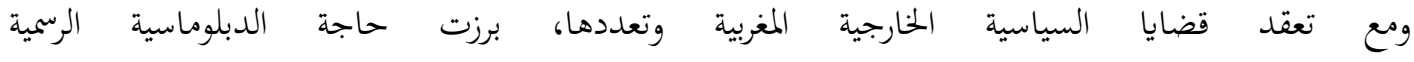

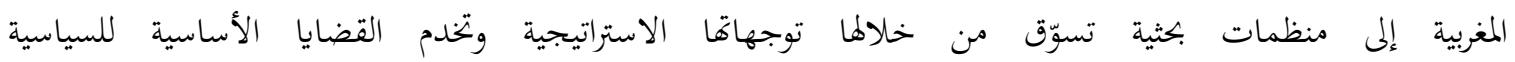

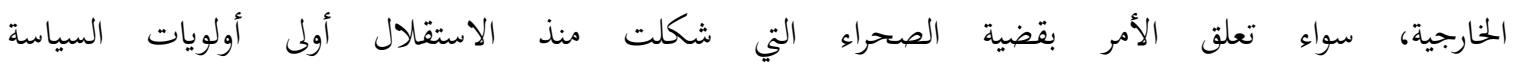

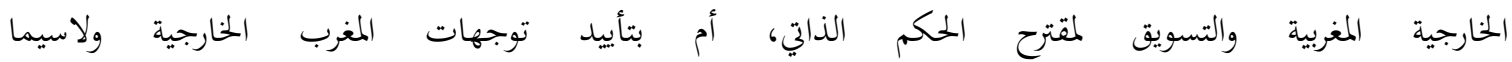

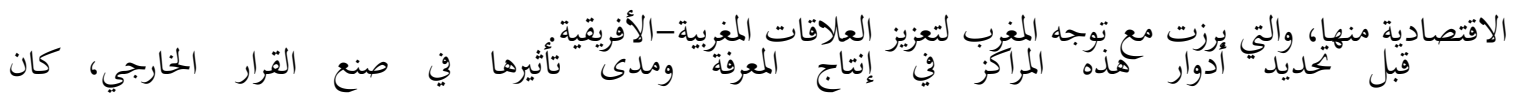

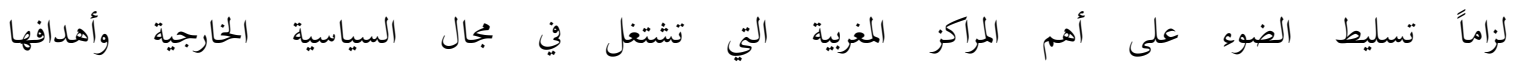

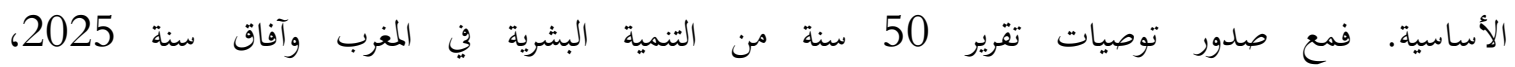
القاضية بتنظيم اليقظة الاستراتيجية واستشراف آفاق المستقبل حول مراكز اليقظة والذكاء الاقتصادي،

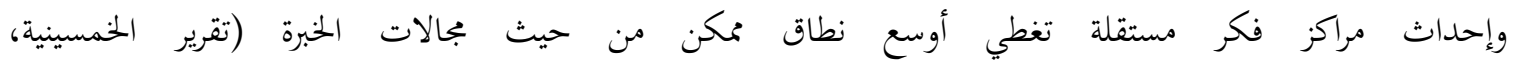

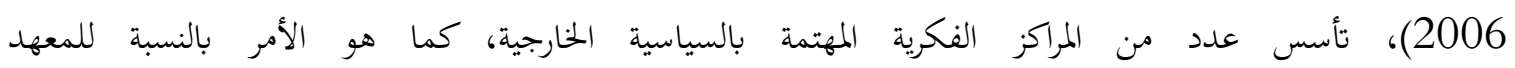

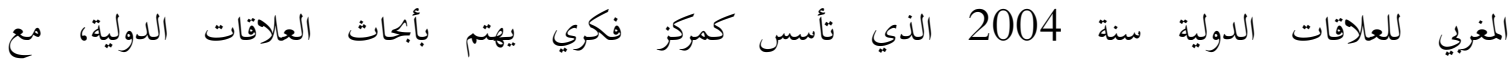
التركيز بشكل خاص على منطقة دول المغرب العربي والبحر الأبيض المتوسط. وتتمحور مشروعاته 
البحثية حول التعاون مع شركاء مغاربة ودوليين، وذلك بشأن عدد كبير من القضايا مثل المساواة بين

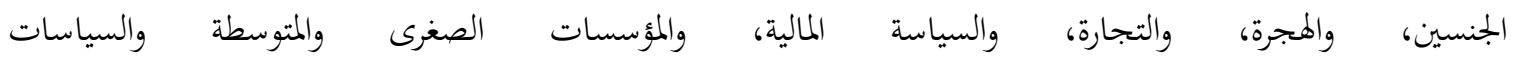

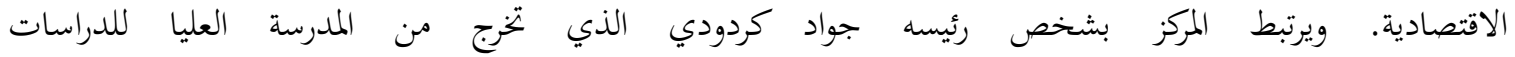
التجارية بباريس سنة 1965، ليشتغل بعد ذلك في مكتب حكومي للصادرات ثم في السلك القنصلي.

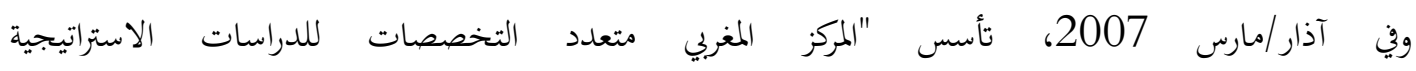

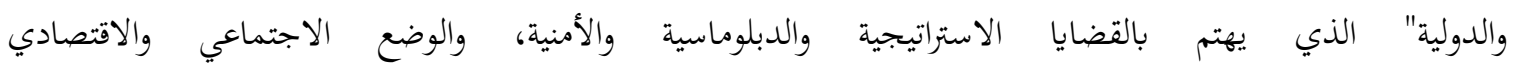
والسياسي. ويهدف هذا المركز الذي يخظى بصفة جمعية ذات نفع عام إلى المساهمة في فهمٍ أفضل

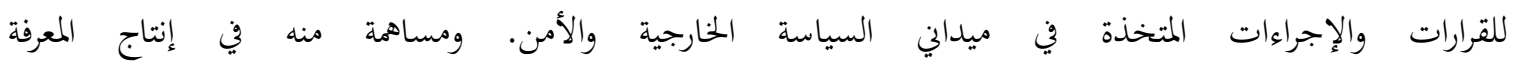
وأمام ندرة الأبحاث الدقيقة في مجال السياسة الخارجية، أصدر المركز "الدليل المغربي للاستراتيجية

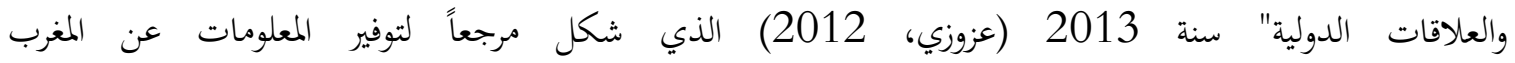

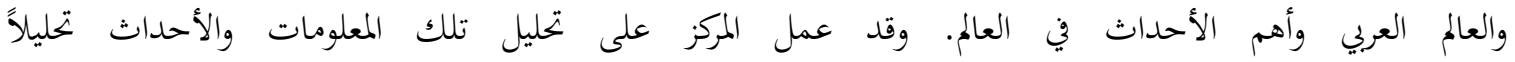

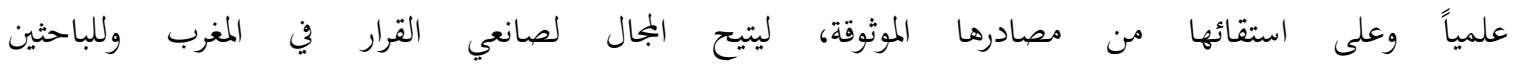

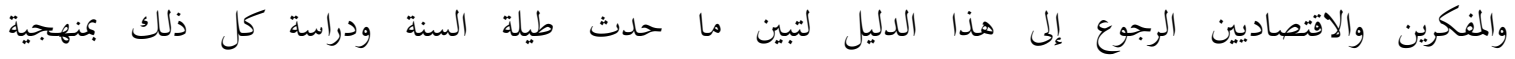
نقدية واستشرافية. يعتبر " المعهد الملكي للدراسات الاستراتيجية" الذي تأسس سنة 2007 من المراكز الأساسية

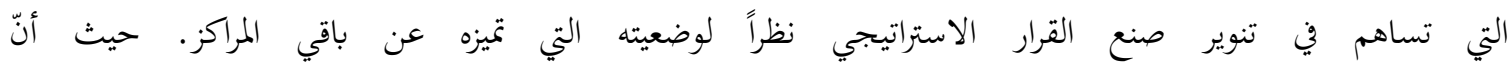

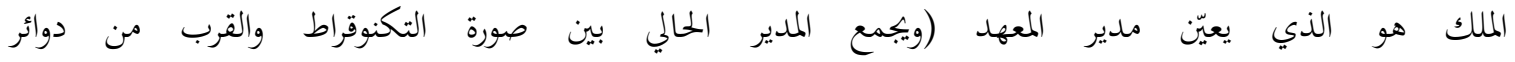

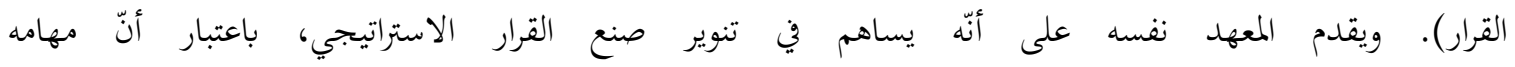

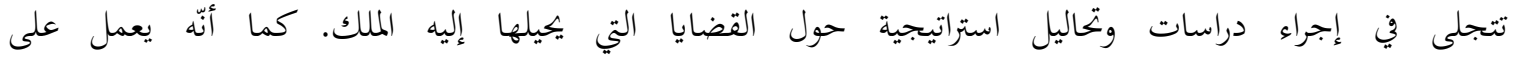

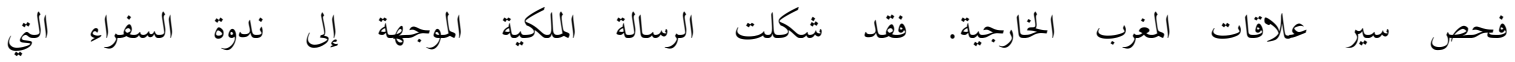
نظمتها في الرباط وزارة الشؤون الخارجية والتعاون من 30 آب/أغسطس إلى 1 أيلول/سبتمبر 2013

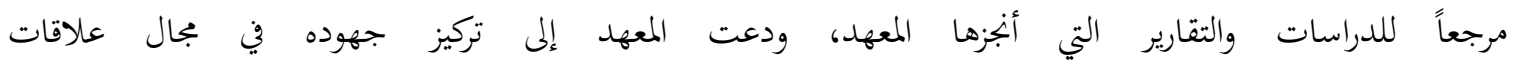

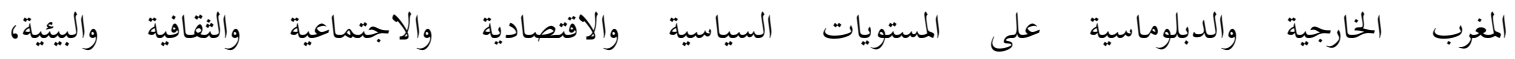

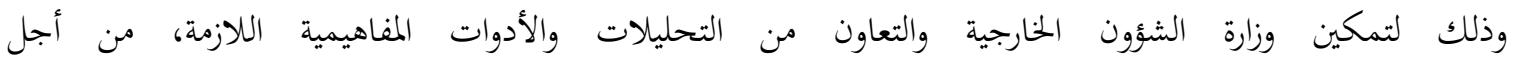
استيعاب التحولات المتسارعة التي يشهدها العالم واستباقها بشكل أفضل التعاون.

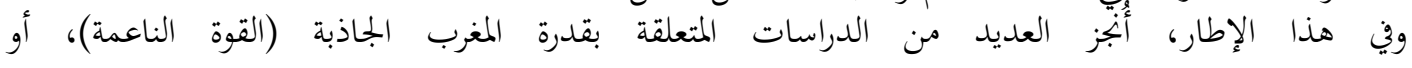

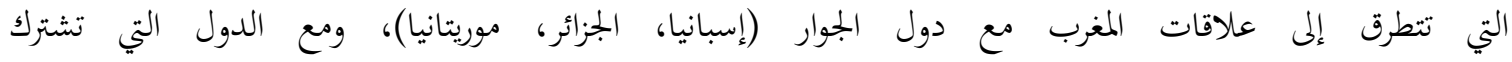

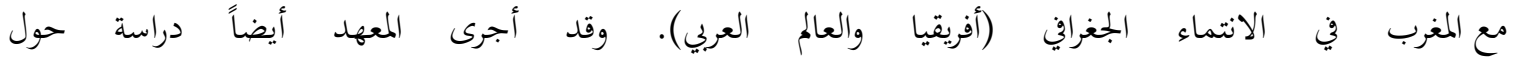

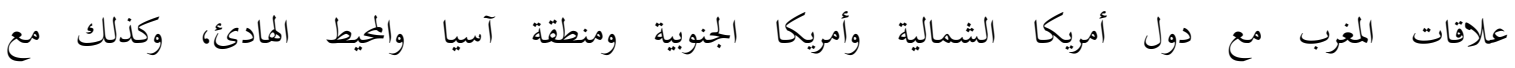
دول بجموعة البريكس. 
كما أولى المعهد اهتماماً خاصاً لقضية الدبلوماسية، حيث أنجز خلال سنة 2015 تقريراً حول

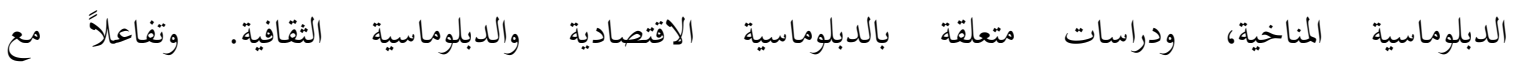

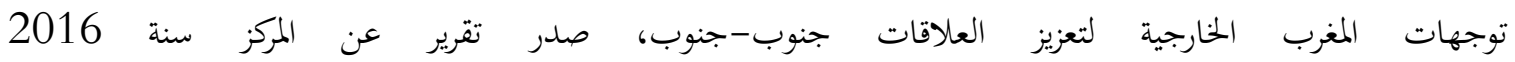

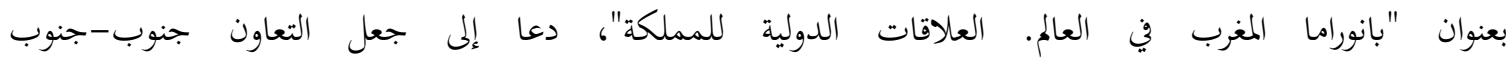

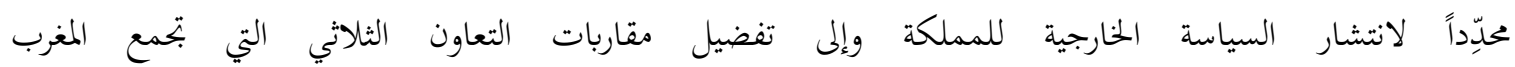
والدول الشريكة من جهة، وأفريقيا وأوروبا من جهة أخرى.

وييين فحص التقارير الصادرة عن المعهد أنّ المشاركين في أبحاثه يتمتعون بهامش مهم للتعبير

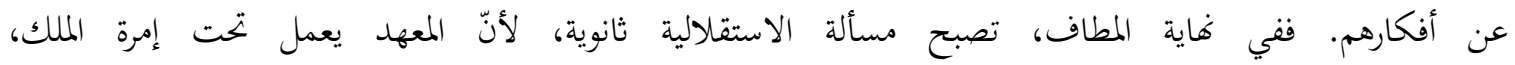

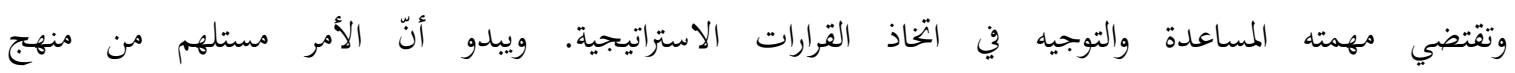

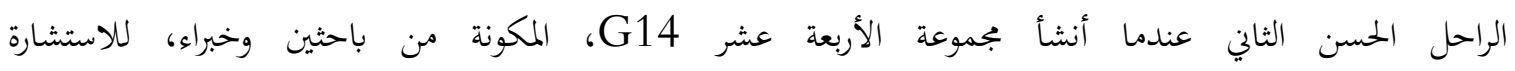

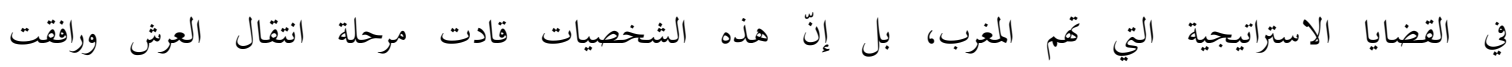

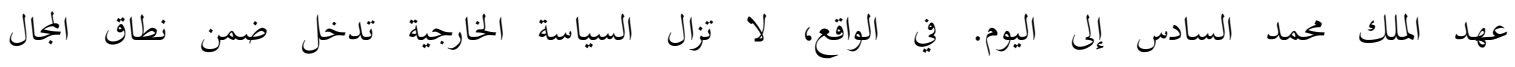

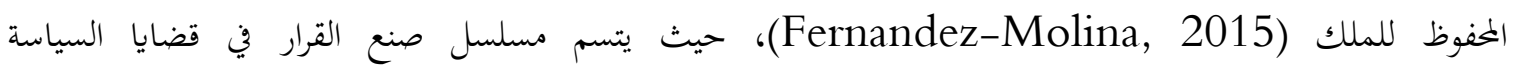

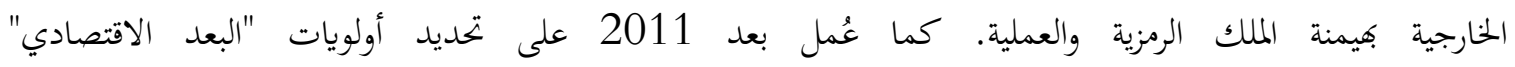

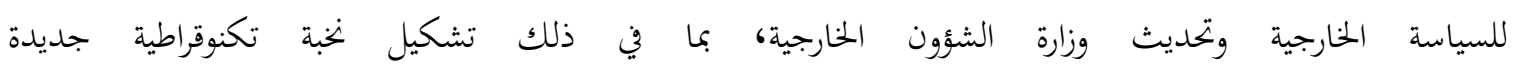

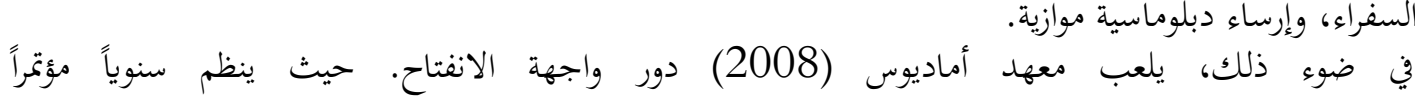

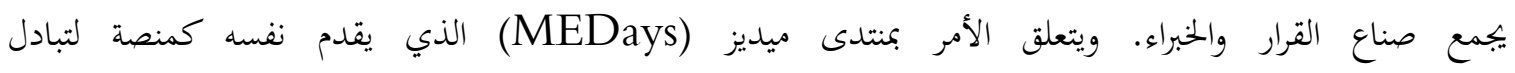

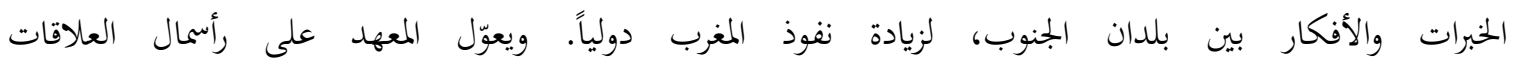

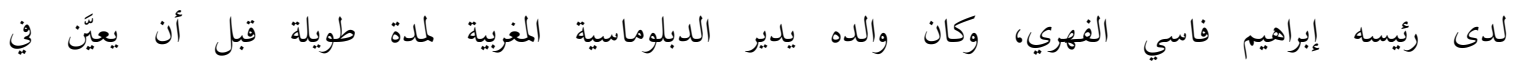

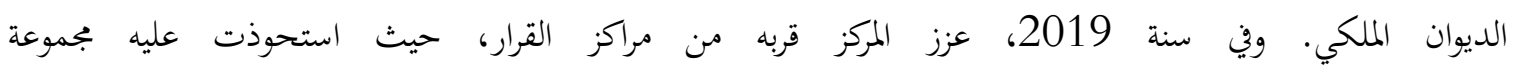
أكوا المملوكة لعائلة عزيز أخنوش، الوزير ذي النفوذ السياسي والاقتصادي القوي.

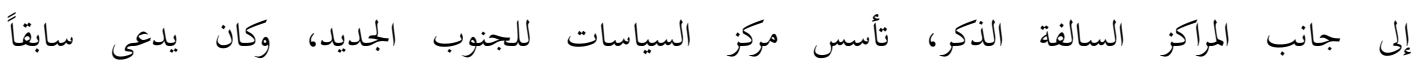

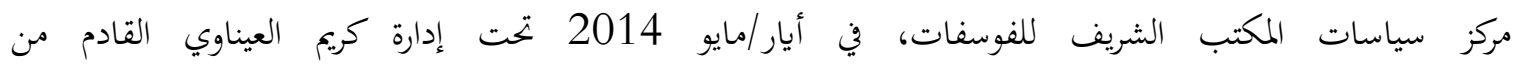

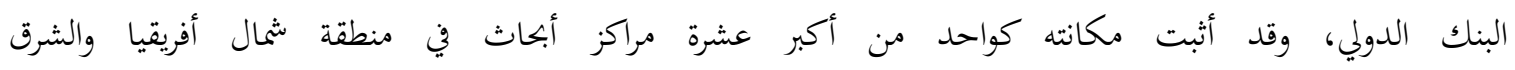

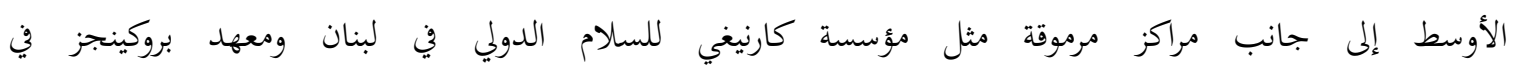

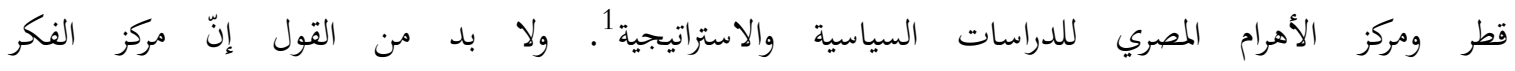

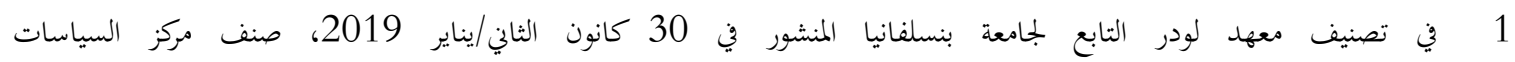

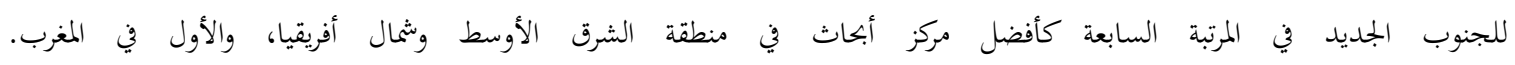

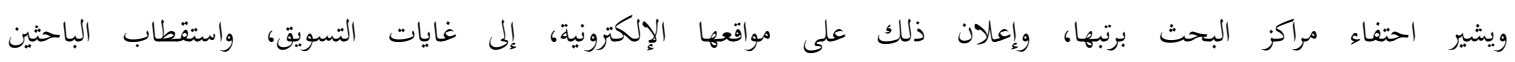
المتعاقدين وتوسيع طلبيات الخبرة والاستشارة. 
المغربي ينشط بشكل كبير على الصعيدين الوطني والدولي في إقامة علاقات مع أبرز نظرائه في العالم.

جدير بالذكر أنّ من بين مهامه تعزيز تبادل المعرفة والمساهمة في إثراء التفكير في القضايا

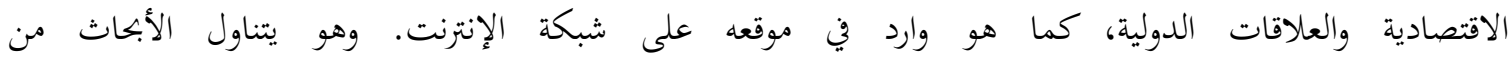

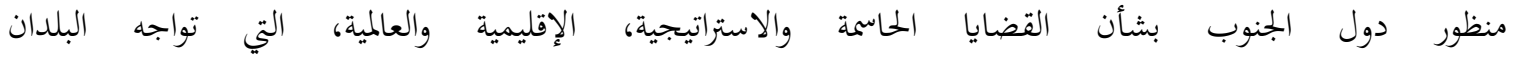
النامية والناشئة.

ويشير احتضان المكتب الشريف للفوسفات لهذا المركز إلى أهمية البعد الاقتصادي في السياسة

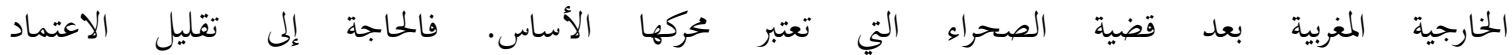

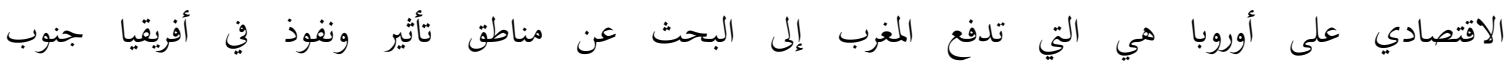

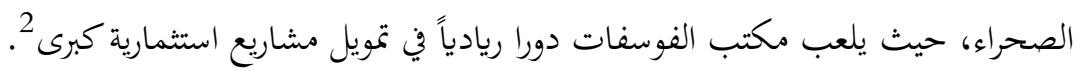

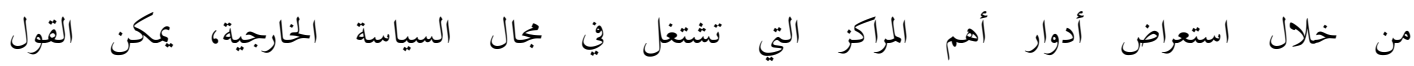

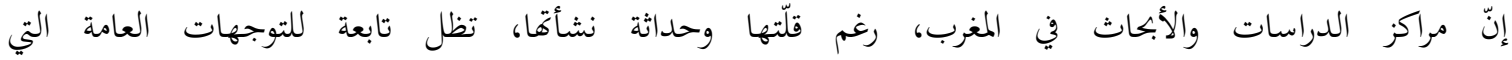

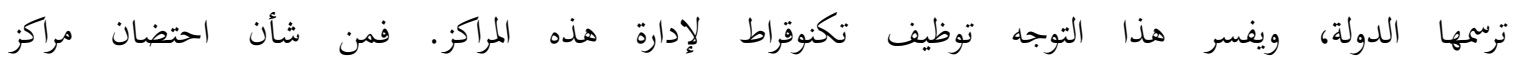

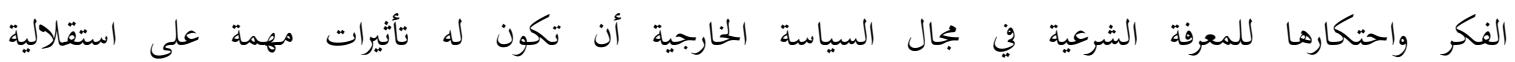

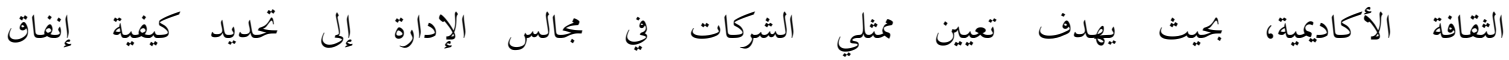

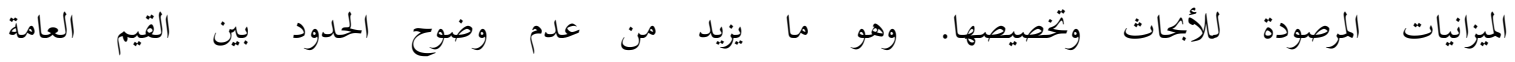
والمصالح التجارية، حيث يتراجع الحافز العلمي للبحث عن الحقيقة أمام دوافع أخرى. فالتزام الباحث

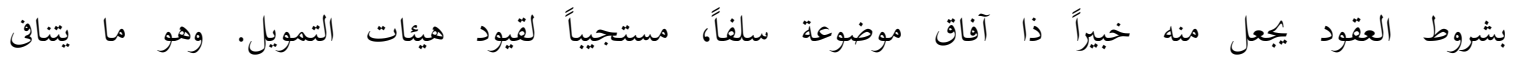

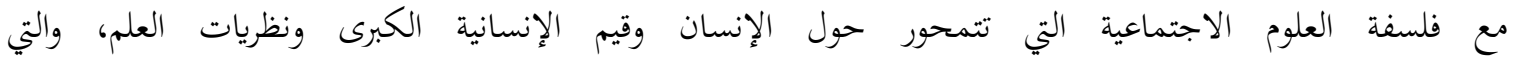

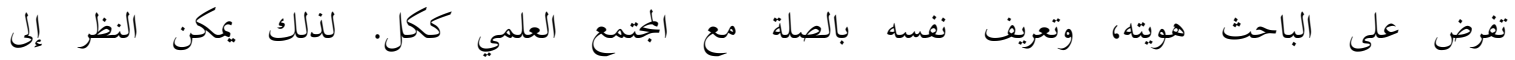

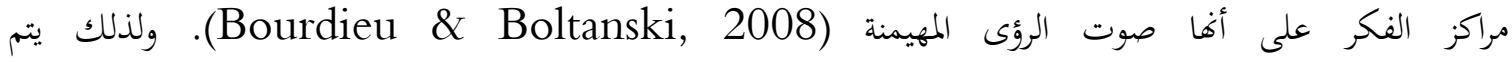

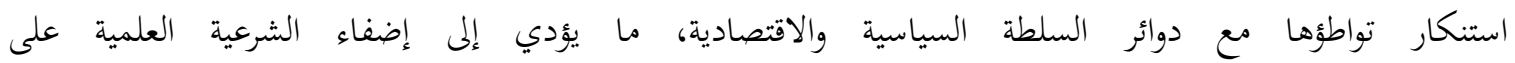

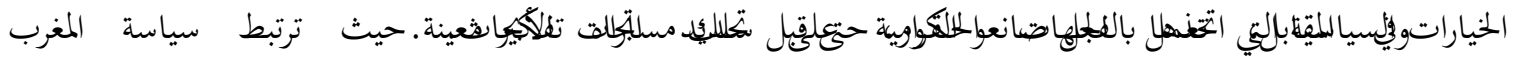

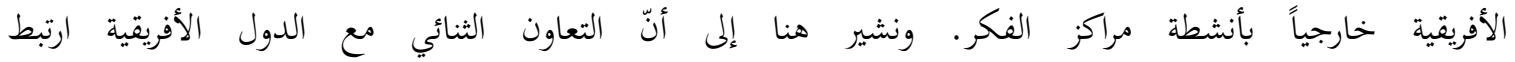

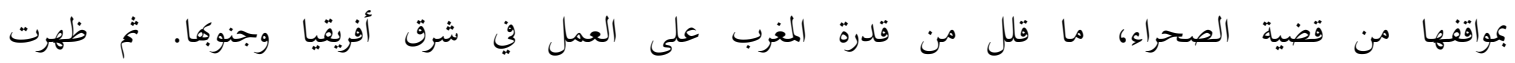

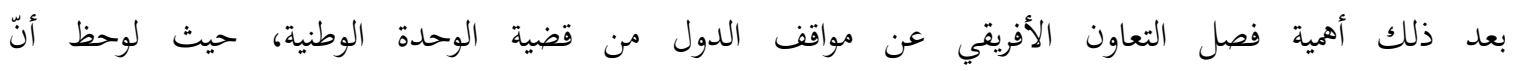

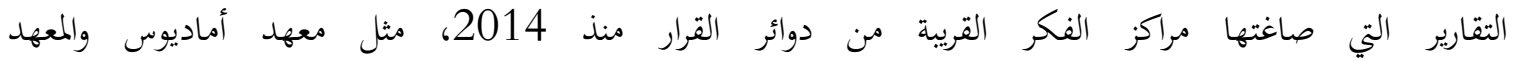
الملكي للدراسات الاستراتيجية، نحت هذا المنحى. كما أنّ البعثة الملكية التي زارت المنات الدول الأفريقية،

2 حافظت مجموعة OCP المغربية على مكانتها كأكبر مصدر للفوسفات في العالم، حيث وصلت حصتها في السوق العالمية إلى 34 بالمئة في أيلول/سبتمبر 2019. 
ومهدت لعودة المغرب لمنظمة الاتحاد الأفريقي، ضمت إبراهيم الفاسي الفهري (معهد أماديوس) إلى آلى

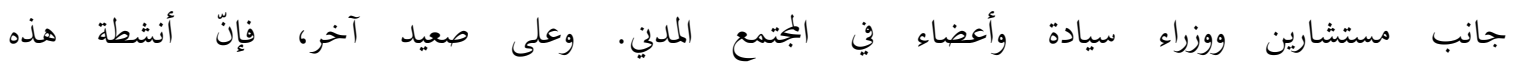

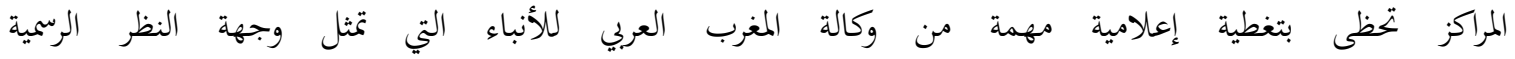

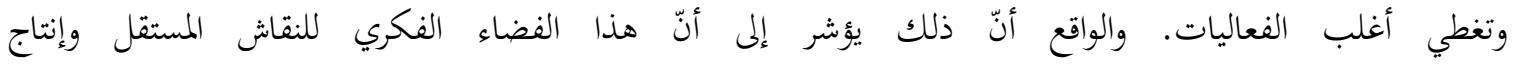

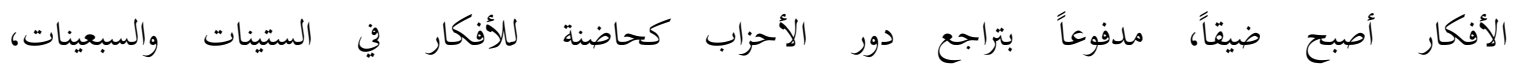

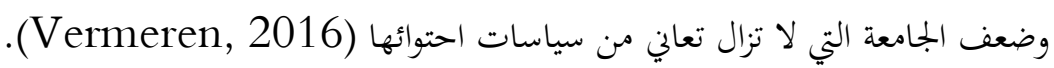

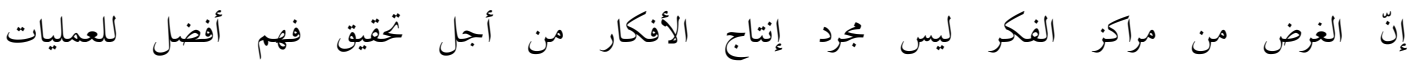

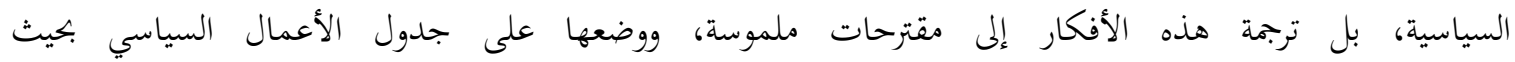

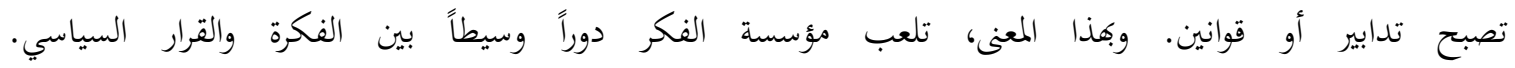

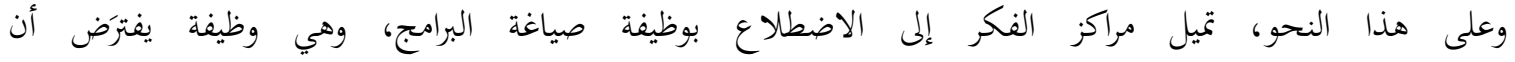

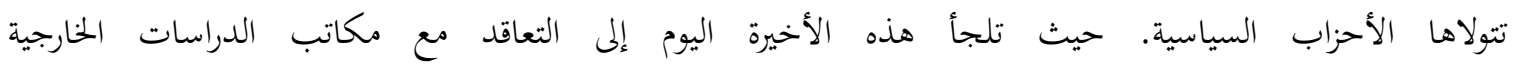

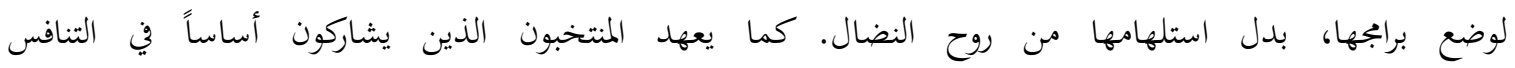

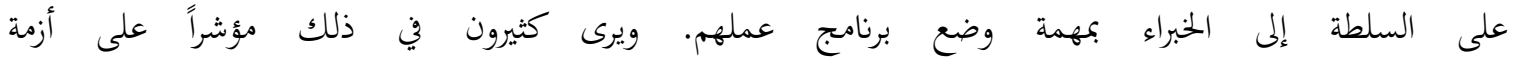

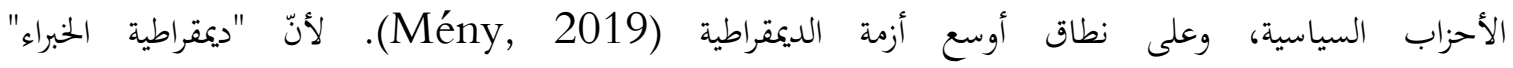

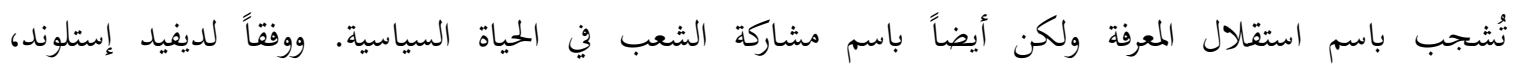

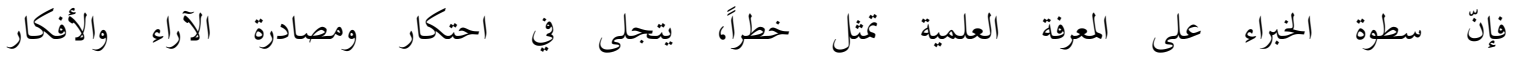

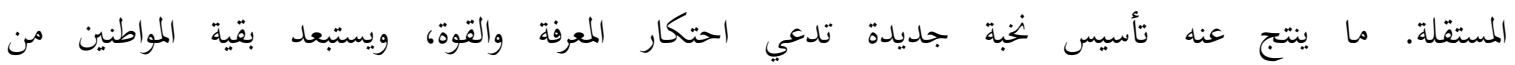

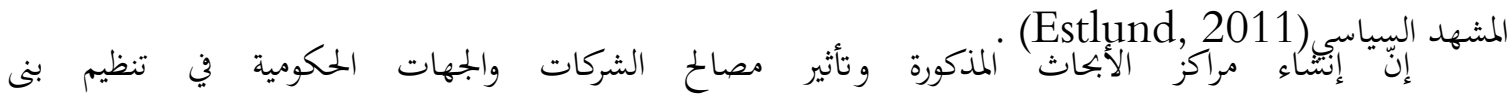

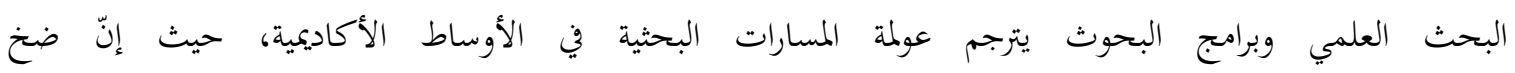

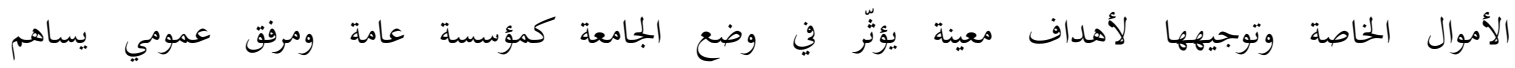

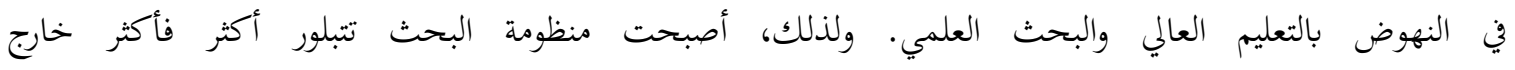

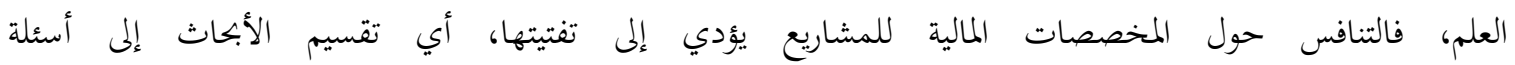

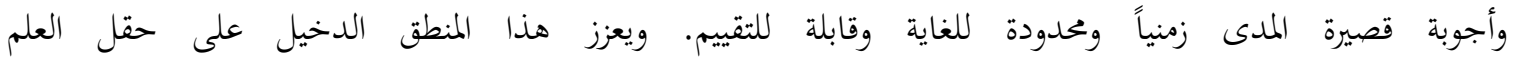

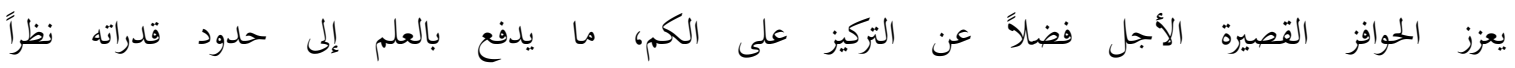

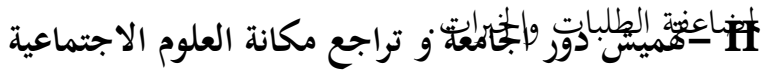

منذ انتهاج سياسات تحرير السوق النيوليبرالية في أوائل الثمانينيات، أصبحت الجامعة أكثر

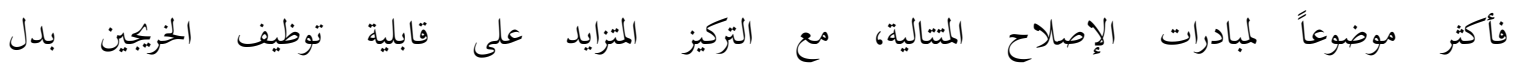

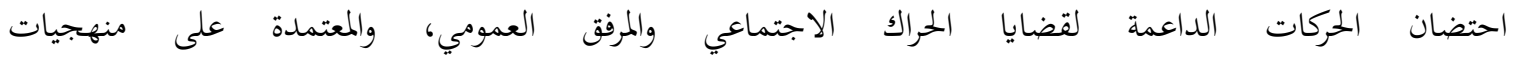

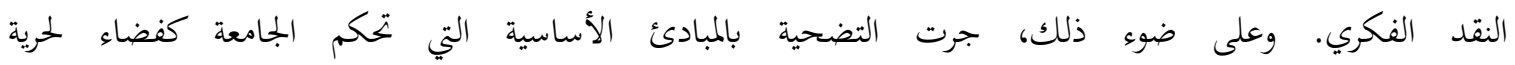

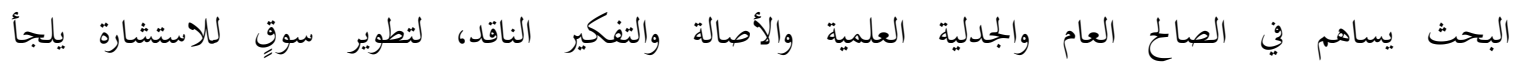


إلى خدمات الخبراء، أو عبر خلق هياكل خارج الجامعات تمارس النشاط البحثي (Giroux, 2002). وقد هُئ لذلك بالترويج في المنابر الإعلامية ذات الطابع الرسمي للأزمة البنيوية للجامعة المغربية وعدم انسجام المعرفة المدرّسة في الجامعات مع متطلبات السوق. كما أنّ مشاهد الاعتصامات و إحباط

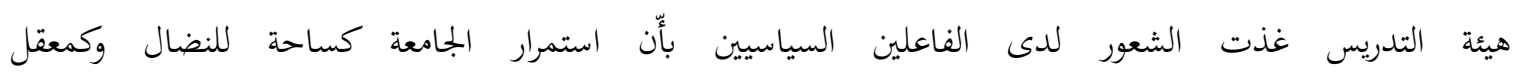
للمعارضة الفكرية يعمق الإشكالات الاجتماعية، وبأنّ اعتماد المسارات المهنية والشهادات الموجهة للسوق يعتبر مفيداً للنخبة الحاكمة، لضبط وتوجيه توجهات الطلاب والباحثين على حد سواء. وفي ذات

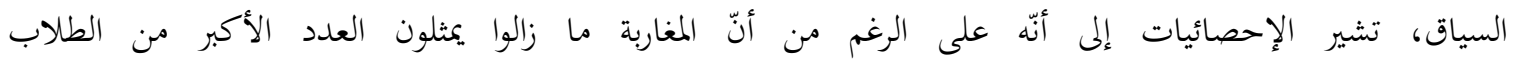

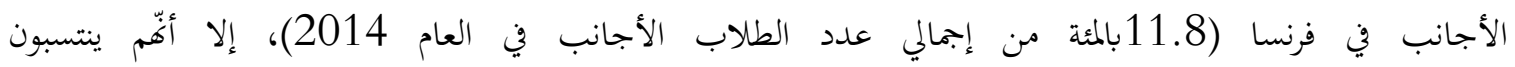

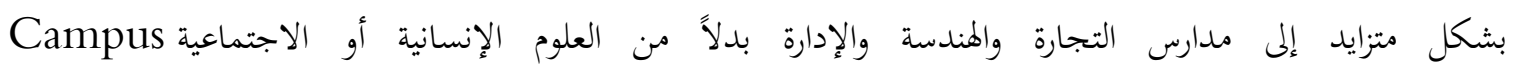

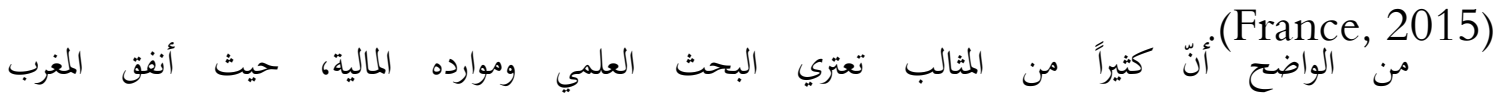

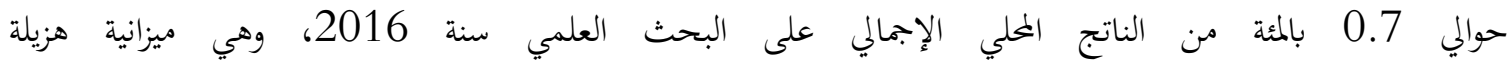

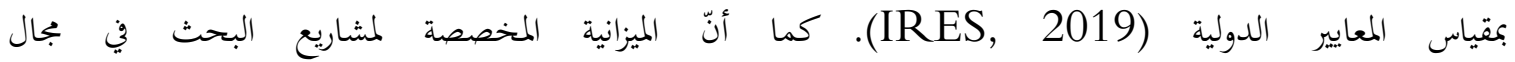
العلوم والتقنيات من المركز الوطني للبحث العلمي والتقني سنة 2013 تفوق عشر مرات التمولمير التمويل المخصص لمشاريع البحث في العلوم الاجتماعية والإنسانية سنة 2018 (CNRST, 2020).

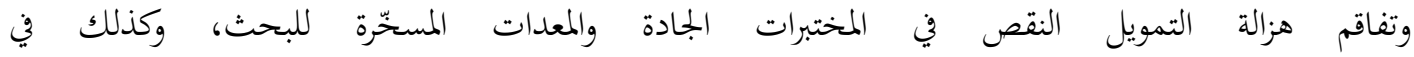
المجلات العلمية الرصينة. كما تؤكد تكلفة نشر الكتب والوضعية السيئة لمكتبات الجامعة على قميش دور الجامعة وإجهاض المبادرات البحثية، حيث يضطر كثير من أعضاء هيئة التدريس للذهاب إلى المكتبة الوطنية في الرباط أو إلى مؤسسة الملك عبد الله بن عبد العزيز آل سعود في الدار البيضاء ولعل من المناسب ألمطبوعات نشير إلى أنّ تقرير "البحث العلمي في المغرب" الذي أنزه معهد البحث من أجل التنمية الفرنسي سنة 2007 خلص إلى أنّ إنتاج أبحاث العلوم الاجتماعية يعتمد على جهود

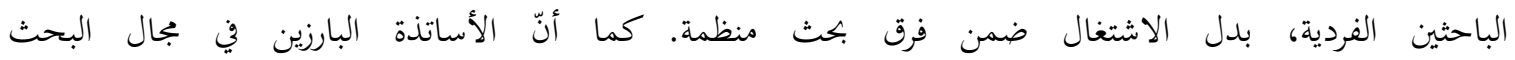
العلمي يهملون تكوين الأجيال الصاعدة من الطلبة الباحثين، مفضلين التوجه نهو خدمات الاستشارة

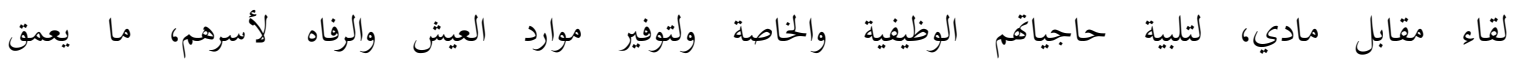

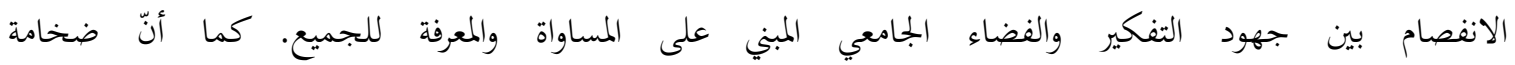
الالتزامات التدريسية واكتظاظ المدرجات بالطلبة يحدّان من مردودية هيئة التدريس، ويعيقان إجراء الأبحاث ونشرها. وهنا لا بد من الإشارة إلى أنّ محاور اهتمام باحثي العلوم الاجتماعية ترتبط بعدد محدود من الموضوعات التي يتم تناولها عادة في المؤتمرات والندوات: الحوكمة، التنمية، النوع الاجتماعي، السياسات العمومية، المجتمع المدني وحقوق الإنسان. والواقع أنّه منذ التسعينات، همشت

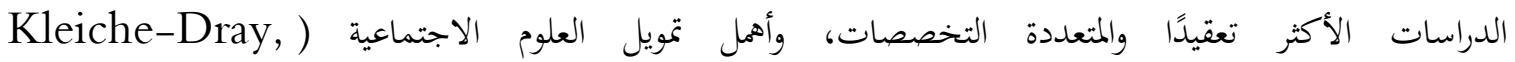

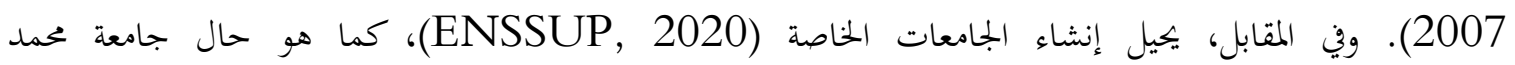


السادس المتعددة التخصصات التقنية بابن جرير، إلى تحويل التعليم، وفق نطاق السوق، نحو المقاولة والابتكار والبعد الأفريقي للمغرب من بين مجالات أخرى. كما تستقطب هذه الجامعة الخاصة مجموعة من الباحثين من مختلف الجنسيات وتبرم اتفاقيات مع مؤسسات مرموقة. غير أنّ انتقائيتها وتبعيتها

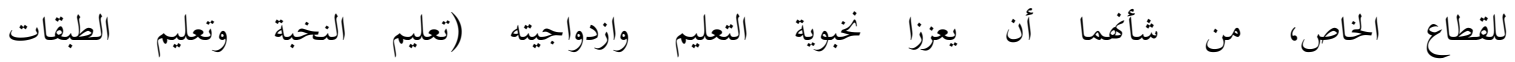
المسحوقة) التي بزغت في فتترة ما بعد الاستعمار (Vermeren, 2002)، بدل (إرساء المساواة والاستقطاب المفتوح.

كما أنّ خصخصة البحث العلمي والافتقار إلى التمويل اللازم للأبحاث الجامعية العمومية قد حدثا بالتوازي مع الانتشار الكبير للمعاهد المهنية الخاصة. وقد بُرّر ذلك بجودة التدريس مقارنة بالجامعات العمومية، لكن الملاحظ أنّ المؤسسات الخاصة دائماً ما تفتقر هي أيضاً إلى برامج أبحاث واضئ واضحة، باستثناءات معدودة. إنّ منطق هذا النموذج هو منطق اقتصادي في الأساس. وهو ينظر إلى المعرفة

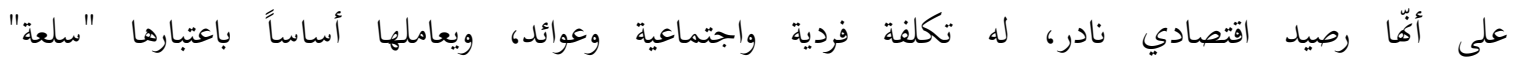

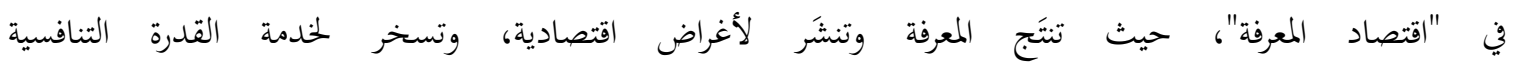
للمنشآت الاقتصادية، ما يؤدي إلى إعادة تنظيم شاملة لإنتاج ونشر المعرفة وفقاً لمعيار السوق ومنطق الشركة. إنّ الأولوية المعطاة للبحث التطبيقي والمسارات المهنية، وكذلك التركيز المتزايد لسياسات

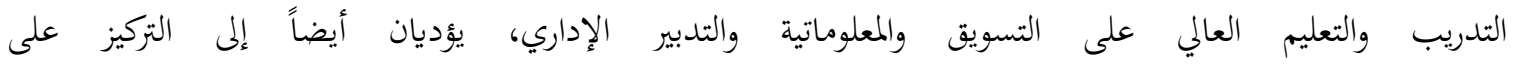
المجالات ذات الأهمية القصيرة المدى (تغليب المصلحة الفورية). ويمكن القول إنّ واحدة من أهم المشكلات الناتحة عن خصخصة مراكز البحث تتجلى في أنّ الأبحاث المنتجة توفر بيانات محدودة

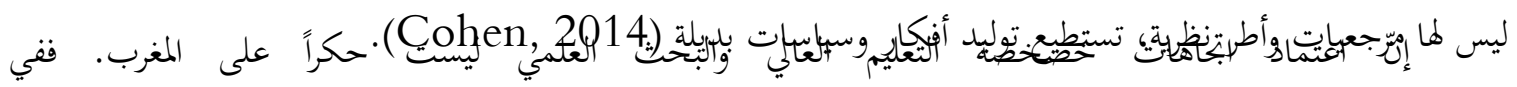

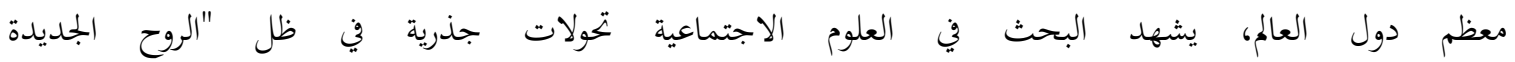

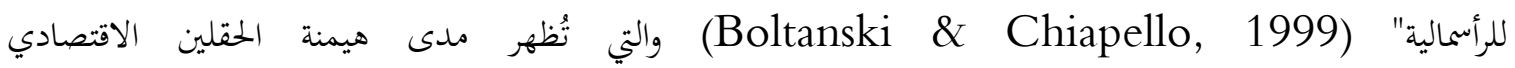
والسياسي. فسياسات البحث التي تضعها الجهات الحكومية ومؤسسات التعاون الأجنبية تعكس اهتمامات الممولين الدولية والتجارية. ومن ثم، فقيام الجامعة بدورها الاجتماعي باستقلالية رهين بتقلبات السياسة الدولية أيضاً. كما أنّه يتعزز في منطقة الشرق الأوسط الافتراض بنهاية الجامعة كفضاء عمومي (Hanafi, 2012). حيث يطغى النموذج السياسي على حوكمة الجامعات العربية بشكل

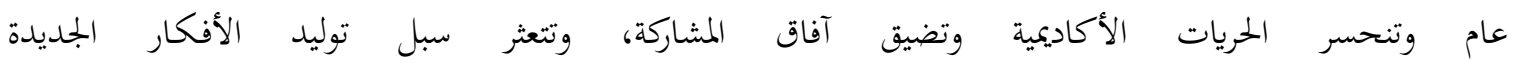
الضرورية للتغيير الاجتماعي (الأمين، 2018).

في ظل سياق يتميز بضعف الاهتمام بالأبحاث في العلوم الاجتماعية، حاول المركز المغربي

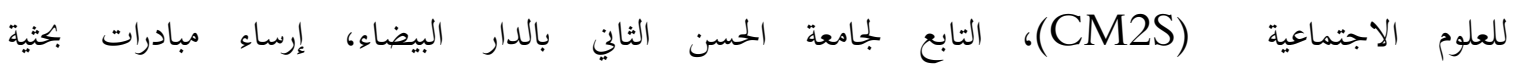
ميدانية أكاديمية، مستفيداً من تجربة القائمين عليه ومن شبكة العلاقات التي ينسجوها مع مع دوائر القرار داخل البلاد وخارجها. حيث يعمل بالشراكة مع منظمات دولية مثل البنك الدولي ومنظمات غير حكومية 
ومؤسسات دولية، مثل مؤسسات التعاون الألمانية (هانس ساديل، كونراد أديناور وفرديرش آيبرت...).

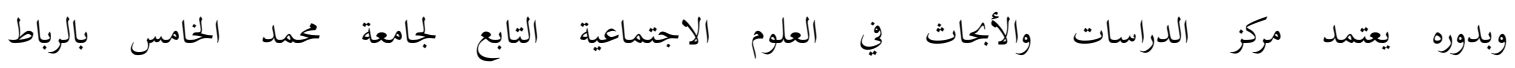

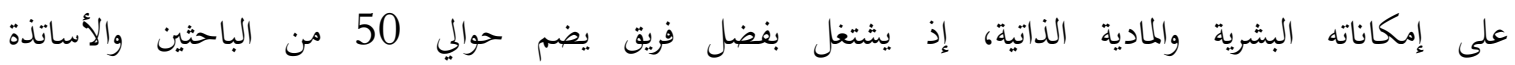

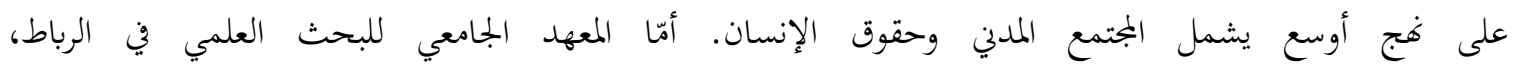

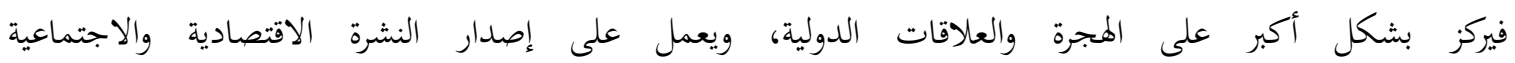

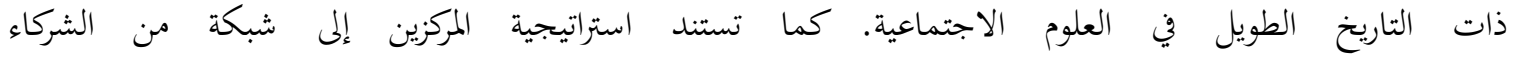
الأوروبيين ومن وكالات التنمية.

وهنا لا بد من بيان أنّ تداخل محاور البحث بين مراكز البحث والمنظمات الدولية يؤدي إلى اعتماد دائرة ضيقة من الباحثين، تشتغل في الوقت ذاته بالتدريس، وتقدم المشورة للجهات الحككومية،

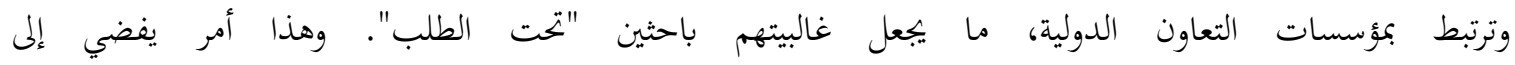
إضفاء الشرعية على التوجهات الحكومية، وعلى خيارات النخب الإدارية.

من خلال التطرق إلى أدوار مراكز البحث بالمغرب في إنتاج المعرفة، يمكنا القول مبدئيا إنّ

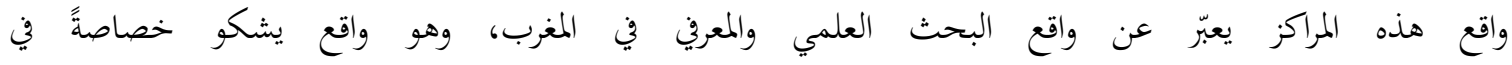

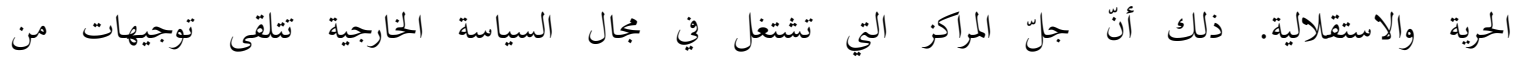

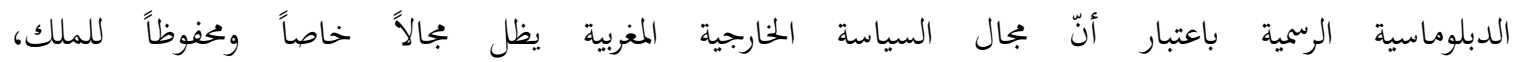

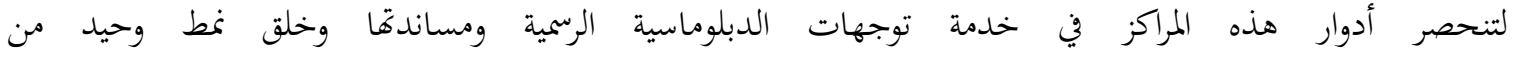

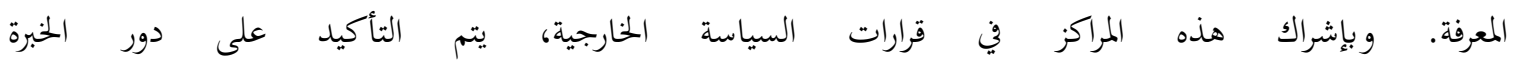

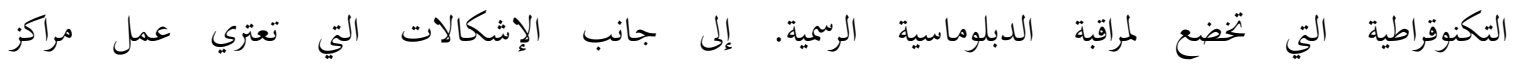

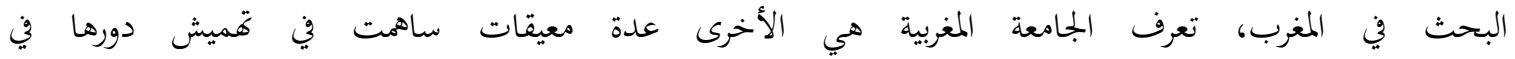

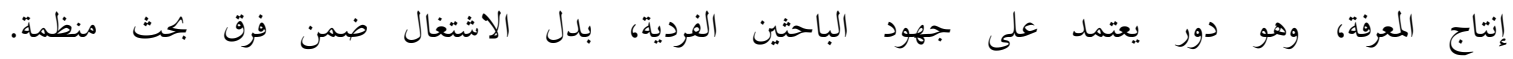
كما أنّ خصخصة البحث العلمي والافتقار إلى التمويل اللازم للأبحاث الجامعية العمومية عاملان البان ساهما

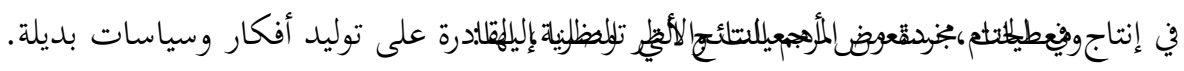

1- إنّ توظيف مراكز الفكر في سياق السياسة الخارجية بلمغرب يتمحور أساساً حول محاور

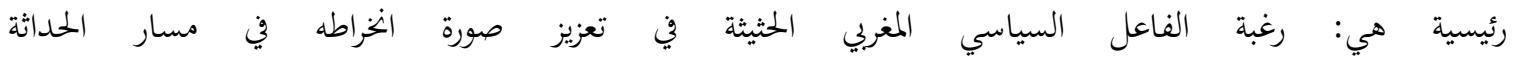

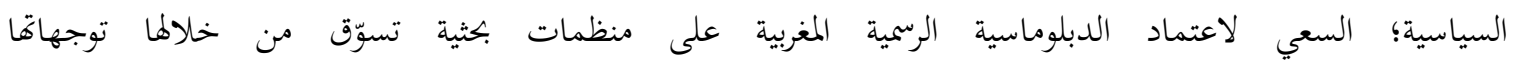

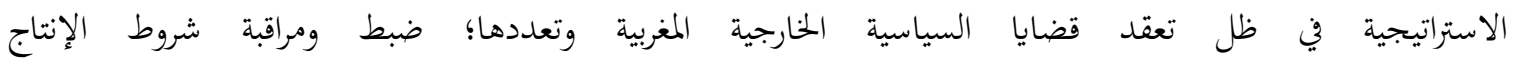


المعريف في هذا البجال لتعزيز هيمنة الفاعلين المركزيين، وتعزيز أولوية المواضيع التي ينغي التطرق لها.

2- إنّ استغلال هذه المشاريع لن يهول دون تعزيز استمرارية هيمنة الملك الرمزية والعملية

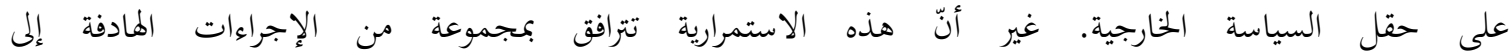
إعادة ترتيب وتحديد الأولويات وبالحاجة إلى التعامل مع مستويات جديدة من واجهات الانفتاح.

3- يشير تزايد التمويل الخاص للعديد من هذه المراكز من طرف شركات مغربية كبيرة (كما هو الأمر بالنسبة لتمويل شركة اكوا القابضة لمعهد اماديوس) إلى أهمية البعد الاقتصادي في المايد السياسة

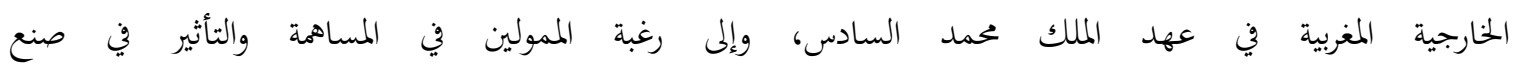
القرارات الاستراتيجية، بما يلائم الطموحات الاقتصادية للأطراف الممولة.

4- إنّ إنشاء مراكز الأبحاث المذكورة وتأثير مصالح الشركات والجهات الحكومية على تنظيم

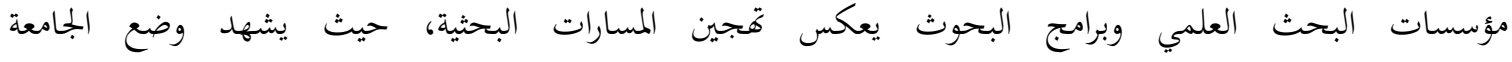
كمؤسسة عامة انتكاسة ملحوظة في النهوض بالتعليم العالي والبحث العلمي. حيث أدت سلطوية النظام،

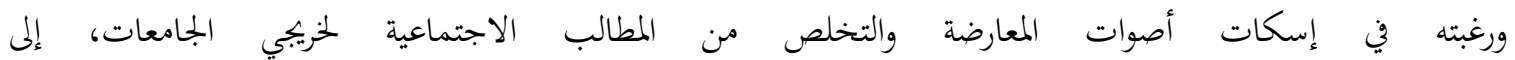

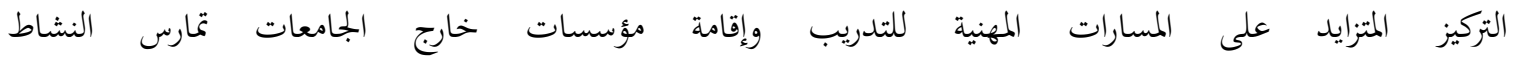

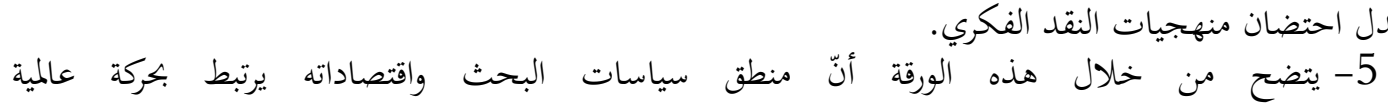

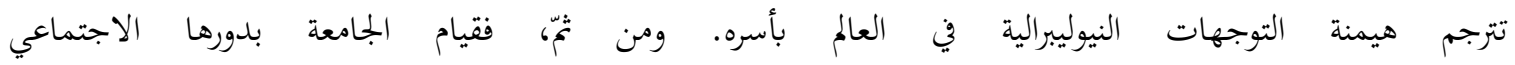

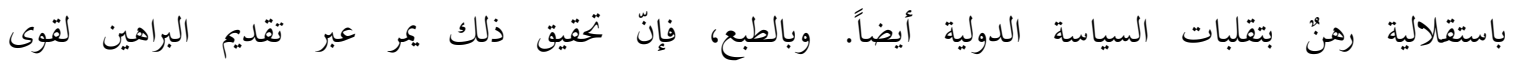

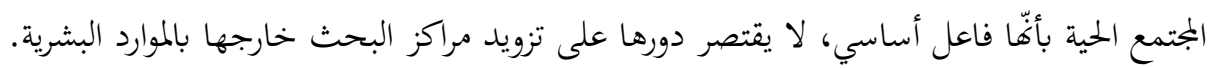

ملخص:

تحف هذه الورقة إلى تسليط الضوء على أدوار مراكز الأبحاث المغربية التي تشتغل في مجال

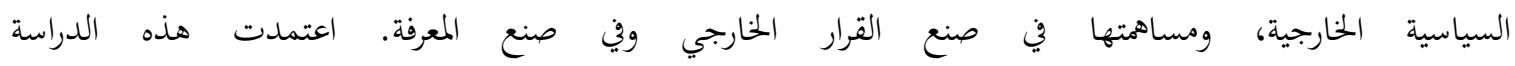

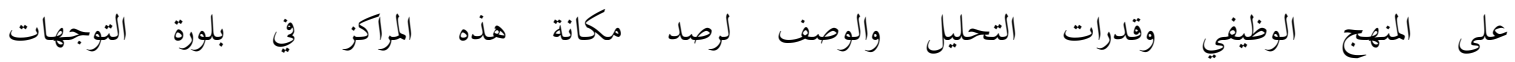

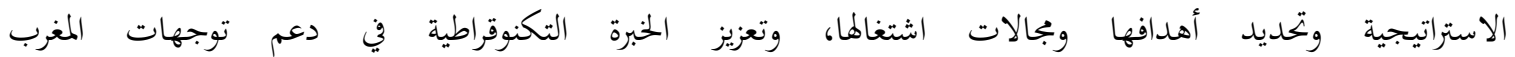

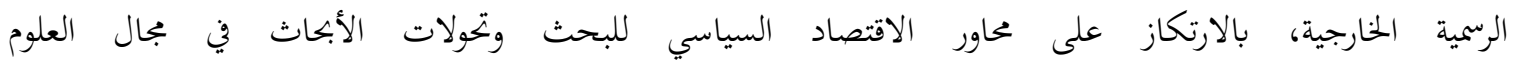

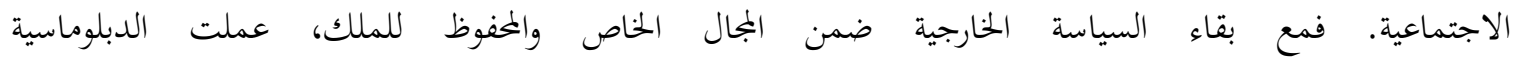
الرممية على إشراك هذه الشبكة من المراكز في قرارات السياسة الخارجية للتسويق لصورة المغرب المبات

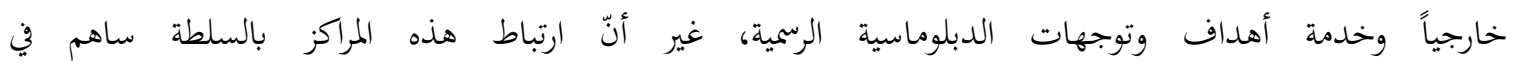
خلق نمط يكاد يكون وحيداً وغير متوازن في ما يتعلق بمنتجي المعرفة المرتبطين بالسياسة الخارجية المغربية، وبشبه تغيبب للجامعة كفضاء للبحث العلمي. 
كلمات مفتاحية:

المراكز البحثية، السياسة الخارجية المغربية، التكنوقراطية، المعرفة، البحث العلمي، الجامعة. 


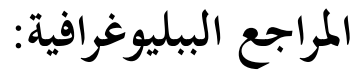 \\ - المراجع العربية}

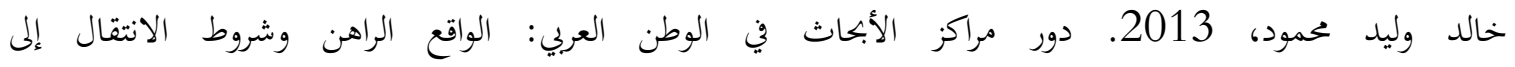

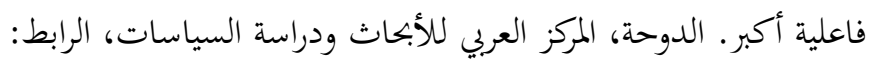

https://www.dohainstitute.org/ar/lists/ACRPSPDFDocumentLibrary/docume nt_4335EE7A.pdf

عبد الحق عزوزي، 2012. الدليل المغربي للاستراتيجية والعلاقات الدولية، فاس، المركز المغربي المتعدد التخصصات للدراسات الاستراتيجية والدولية.

عدنان الأمين، 2018. الجامعات العربية وتحديات التغير الاجتماعي، مجلة عمران، العدد 26، ص. $84-61$

اللجنة المديرية، 2006. [تقرير الحمسينية]: المغرب الممكن: إسهام في النقاش العام من أجل طموح مشترك. الدار البيضاء: دار النشر المغربية. - II

Boltanski Luc \& Chiapello Ève, 1999. Le nouvel esprit du capitalisme, Paris, Gallimard (NRF Essais).

Bourdieu Pierre \& Boltanski Luc, 2008. La Production de l'idéologie dominante, Paris, Raisons d'agir/Demopolis.

Campus France, 2015. Les notes, Septembre 2015, URL: https://ressources.campusfrance.org/publications/notes/fr/note_14_hs_fr.pdf

CNRST, CNRST en chiffres, 25 Juillet 2020, URL: https://www.cnrst.ma/index.php/fr/cnrst/a-propos/cnrst-en-chiffres

Enseignement Supérieur et de la Recherche Scientifique (ENSUP), 2020. Liste des universités privées, 
URL: $\quad$ https://www.enssup.gov.ma/sites/default/files/ETABLISSEMENTSUP/125/Liste-universites-privees-autorisees_2019-2020.pdf

Cohen Shana, 2014. "Neoliberalism and Academia in Morocco", British Journal of Middle Eastern Studies, nº41, p. 28-42

Estlund David M., 2011. L'autorité de la démocratie : une perspective philosophique, Paris, Hermann

Fernandez-Molina Irene, 2015. Moroccan Foreign Policy under Mohammed VI, 1999-2014, New York, Routledge

Giroux Henry, 2002. "Neoliberalism, Corporate Culture, and the Promise of Higher Education: The University as a Democratic Public Sphere", Harvard Educational Review, n²(4), p. 245-263

Hanafi Sari, 2012. "Les systèmes universitaires au Moyen-Orient arabe”, Revue des mondes musulmans et de la Méditerranée, n¹31, p. 23-44, URL : https://journals.openedition.org/remmm/7579

IRES, 2019. La recherche scientifique et l'innovation dans le monde arabe, URL: https:/www.ires.ma/wp-content/uploads/2019/07/RAPPORT-RSIdans-le-monde-arabe.pdf

Kleiche Dray Mina, 2007. La recherche scientifique au Maroc : rapport de synthèse, Rabat (MAR), Paris, IRD

Mény Yves, 2019. "La technocratie : auxiliaire démocratique ou bouc émissaire du «peuple»? ”. in Y. Mény (dir.), Imparfaites démocraties, Paris, Presses de Sciences Po, p. 119-159

Vermeren Pierre, 2002. La Formation des élites marocaines et tunisiennes. Des nationalistes aux islamistes, 1920-2000, Paris, La Découverte

Vermeren Pierre, 2016. Histoire du Maroc depuis l'indépendance, Paris, La Découverte 